\title{
Availability and Use of Health Research Information in and for Low- and Middle-Income Developing Countries — Manila Declaration
}

\author{
doi: http://dx.doi.og/10.3329/jemc.v6i1.26372
}

This declaration was launched at the 2015 Convention of the Asia Pacific Association of Medical Journal Editors (APAME 2015) held in Manila from 24 to 26 August 2015 in conjunction with the Global Forum on Research and Innovation for Health (FORUM 2015). It is concurrently published by Journals linked to APAME and listed in the Index Medicus of the South East Asia Region (IMSEAR) and the Western Pacific Region Index Medicus (WPRIM). Journals indexed on WPRIM and IMSEAR may co-publish the declaration as a Special Announcement. As Journal of Enam Medical College is indexed in IMSEAR, this declaration is being reproduced in Journal of Enam Medical College.

We, the participants in the Joint Meeting of the Asia Pacific Association of Medical Journal Editors (APAME), the Index Medicus of the South East Asia Region (IMSEAR), and the Western Pacific Region Index Medicus (WPRIM) held in Manila from 24 to 26 August 2015, in conjunction with the Global Forum on Research and Innovation for Health held in Manila from 24-27 August 2015, drawing on the Pre-Forum Discussions on HIFA from 20 July to 24 August 2015 "Meeting the information needs of researchers and users of health research in low- and middle-income countries" available at http://www.hifa2015.org/ meeting-the-information-needs-of-researchers-andusers-of-health-research-2/ and the BMJ Blogs 20 July 2015 "How can we improve the availability and use of health research in developing countries?" available at http://blogs.bmj.com/bmj/2015/07/20/how-can-weimprove-the-availability-and-use-of-health-research-indeveloping-countries/ :

\section{CONSIDERING}

That the WHO Constitution "enshrines the highest attainable standard of health as a fundamental right of every human being;" and that "The right to health includes access to timely, acceptable, and affordable health care of appropriate quality ... as well as the underlying determinants of health, such as ... access to health-related education and information;"

That increasing the availability of health research is fundamental to global health and the progressive realization of the right to health, and that researchers, policymakers, health professionals, and citizens need access to peer-reviewed research, relevant to their context, and in a language they can understand;
That despite a growing momentum toward free and open access to research, and important initiatives that have helped to improve the availability of research in low- and middle-income developing countries, there continue to be many limitations and exclusions that prevent health research information from becoming freely available to those who need it;

That the Global Health Library (GHL), Index Medicus of the South East Asia Region (IMSEAR), Western Pacific Region Index Medicus (WPRIM), and Asia Pacific Association of Medical Journal Editors (APAME) are important collaborative initiatives that can promote and uphold the availability and use of health research information especially in and for lowand middle-income developing countries;

\section{CONFIRM}

Our commitment to champion and advocate for the increased visibility and accessibility of health research information from and to low- and middle-income developing countries through our Journals, our respective National Associations of Medical Editors, and APAME;

Our commitment to make research freely available in the right language to producers and consumers of health research in low- and middle-income countries through IMSEAR, WPRIM, the Asia Pacific Medical Journal Articles Central Archives (APAMED Central) and other platforms;

Our commitment to improve access to and dissemination of the different formats of health information required by different users in different contexts including through such non-traditional channels of dissemination as social media, communities of practice, blogs and mobile devices; 


\section{CALL ON}

Member States of and governments in the South East Asia and Western Pacific Regions, in collaboration with stakeholders from the non-government and private sectors to formulate and implement policies and certification schemes such as the COHRED Fairness Index ${ }^{\mathrm{TM}}(\mathrm{CFI})$ that promote free and open availability of health research information for both its producers and consumers, especially in low- and middle-income developing countries;

Stakeholders from the public and private sectors, national and international organizations, universities and academic societies, and discussion groups such as Healthcare Information for All (HIFA2015) to support IMSEAR, WPRIM, the GHL, APAMED Central, and similar initiatives, in order to ensure the free and global accessibility of health research done in the South East Asia and Western Pacific Regions;

The Eastern Mediterranean Association of Medical Editors (EMAME), the Forum for African Medical Editors (FAME), the Pan American Health Organization (PAHO), the European Association of Science Editors (EASE), the World Association of Medical Editors (WAME), the International Committee of Medical Journal Editors (ICMJE), the Committee on Publication Ethics (COPE) and other editors' and publishers' associations to support APAME in implementing various activities, guidelines and practices that would improve the quality of scientific writing and publications in the Asia Pacific Region and the world;

Bibliographic Databases such as HINARI, PubMed, Global Health Database (CAB Direct), EMBASE,
SciELO Citation Index, Scopus, and the Web of Science to review their policies and processes for indexing Journals from low- and middle-income developing countries, as well as making health research information freely available to users in these countries who cannot afford to pay for it;

\section{COMMIT}

Ourselves and our Journals to publishing innovative and solution-focused research in all fields of medicine, public health, nursing, dentistry, pharmacy, other health professions, and health promotion, particularly research applicable to low- and middle-income countries;

Our publishers, to disseminating scientific and medical knowledge fairly and impartially through Bibliographic Databases including, but not limited such Regional Indexes of the Global Health Library as the African Index Medicus (AIM), Latin-American and Caribbean System on Health Sciences Information (LILACS), Index Medicus for the Eastern Mediterranean Region (IMEMR), IMSEAR, WPRIM;

Our organization, APAME, to building further networks, convening conferences, and organizing events to educate and empower editors, peer reviewers, authors, librarians and publishers to achieve real impact, and not just impact factor, as we advance access to health information and publication that addresses the greatest global health concerns.

26 August 2015, Manila

Copyright (C) APAME. www.wpro.who.int/apame apame@wpro.who.int 